\title{
Non-ablative Fractional Laser as an Emerging Treatment for
}

\section{Alopecia Areata}

\section{Junqueira $\mathrm{LA}^{1,2 *}$, Carniello AE ${ }^{1}$, Fabri Mazza $\mathbf{M}^{1,2}$ and Junqueira}

\section{Bertin $\mathrm{AC}^{1}$}

${ }^{1}$ Instituto Brasileiro de Ensino e Pesquisas em Medicina Capilar- IBEMC, Brazil

2Department of Dermatology, Hospital Heliópolis, Brazil

*Corresponding author: Ana Lucia Junqueira, nstituto Brasileiro de Ensino e

\section{Case Report}

Volume 4 Issue 4

Received Date: November 25, 2019

Published Date: December 19, 2019

DOI: $10.23880 /$ cdoaj-16000196

Pesquisas em Medicina Capilar- IBEMC, Rua Groenlandia, 462 São Paulo- SP, Brazil, Tel: +5511941228978; Email: anajunqueira12@hotmail.com

\section{Abstract}

Alopecia areata (AA) is a complex autoimmune non scarring type of hair loss that may affect any hair-bearing area. Although there is still no treatment modality approved by the US Food and Drug Administration, topical and intralesional corticosteroids are most commonly used with variable resuts. More recently, laser treatment have been proposed to induce hair growth. Fractional non- ablative lasers produce a controlled injury in the tissue, thus creating a wound healing process that could stimulate hair regrowth. The small wounds formed stimulate changes in cytokines and growth factors expression, allow a rapid epidermal repair and a premature anagen entry. The aim of this report is to demonstrate two cases of extensive AA succesfully treated with intralesional corticosteroids and fractionated laser, reinforcing the therapeutic potential of laser treatment for hair loss.

Keywords: Alopecia areata; Fractional laser; Intralesional corticosteroid

\section{Introduction}

Alopecia areata (AA) is an immune mediated non scarring type of hair loss that can affect males and females at all ages. It has a lifetime risk estimated of $1,7 \%-2,1 \%$ $[1,2]$. The most commom clinical patterns are patchy alopecia (localized round or oval areas of alopecia), alopecia totalis (loss of all scalp hair), alopecia universalis (loss of all scalp and body hair) and ophyasis pattern (alopecia of the periauricular área and the lower occipital scalp). AA may also affect nails, eyelashes, eyebrows and other body hairs. Extensive and/or persistent cases can cause severe psychologycal distress.
There is currently no drug approved by the Food and Drug Administration (FDA) for the treatment of this disease, however topical and intralesional corticosteroids are commomly used with variable results [3].

More recently, another approach for AA that have been reported in the literature is the use of fractional lasers $[4,5]$.

In here we report on two cases of extensive alopecia areata treated with combination of intralesional corticosteroids followed by fractionated laser photothermolyses. 


\section{Case Reports}

For intralesional injections, a combination of triamcinolone acetonide $20 \mathrm{mg} / \mathrm{mL}$ and lidocaine hydrochloridre $2 \%$ with epinephrine were used, in a final concentration of $5 \mathrm{mg} / \mathrm{mL}$ of the corticosteroid.

Laser treatment was performed with a non-ablative $1550 \mathrm{~nm}$ fractional erbium glass laser (Fraxel $®$, Solta Medical, Hayward, CA). At each laser session, eight passes per affected area were performed, at $10 \mathrm{~mJ}$ of energy and density of $672 \mathrm{MTZ} / \mathrm{cm} 2$.

\section{Case 1}

A 24-year old female with a 4 years history of alopecia areata totalis, presented total scalp hair loss and hair loss of the distal third of the left eyebrow (Figures 1A-C).
Eyelashes and body hair were not affected. The patient received $6 \mathrm{ml}$ of intralesional injections of triamcinolone and lidocaine at each treatment session. A vibratory device (Brookstone ${ }^{\circledR}$ ) was used during the procedure to minimize the pain. After injections, fractional laser was applied to the entire scalp. Treatment was performed once a month, for 6 months. The patient was already using clobetasol shampoo before the treatment, without any significant improvement. She was advised to continue applying the shampoo 3 times a week. After 4 months, she had developed isles of regrowth diffusely, with thick and pigmented terminal hairs (Figures 1D-F). A few areas of atrophy on the scalp could also be observed. Injection was avoided in those atrophic areas in the remaining sessions. After 6 months, she presented with more areas of regrowth and overall improvement (Figures 1G-1I).
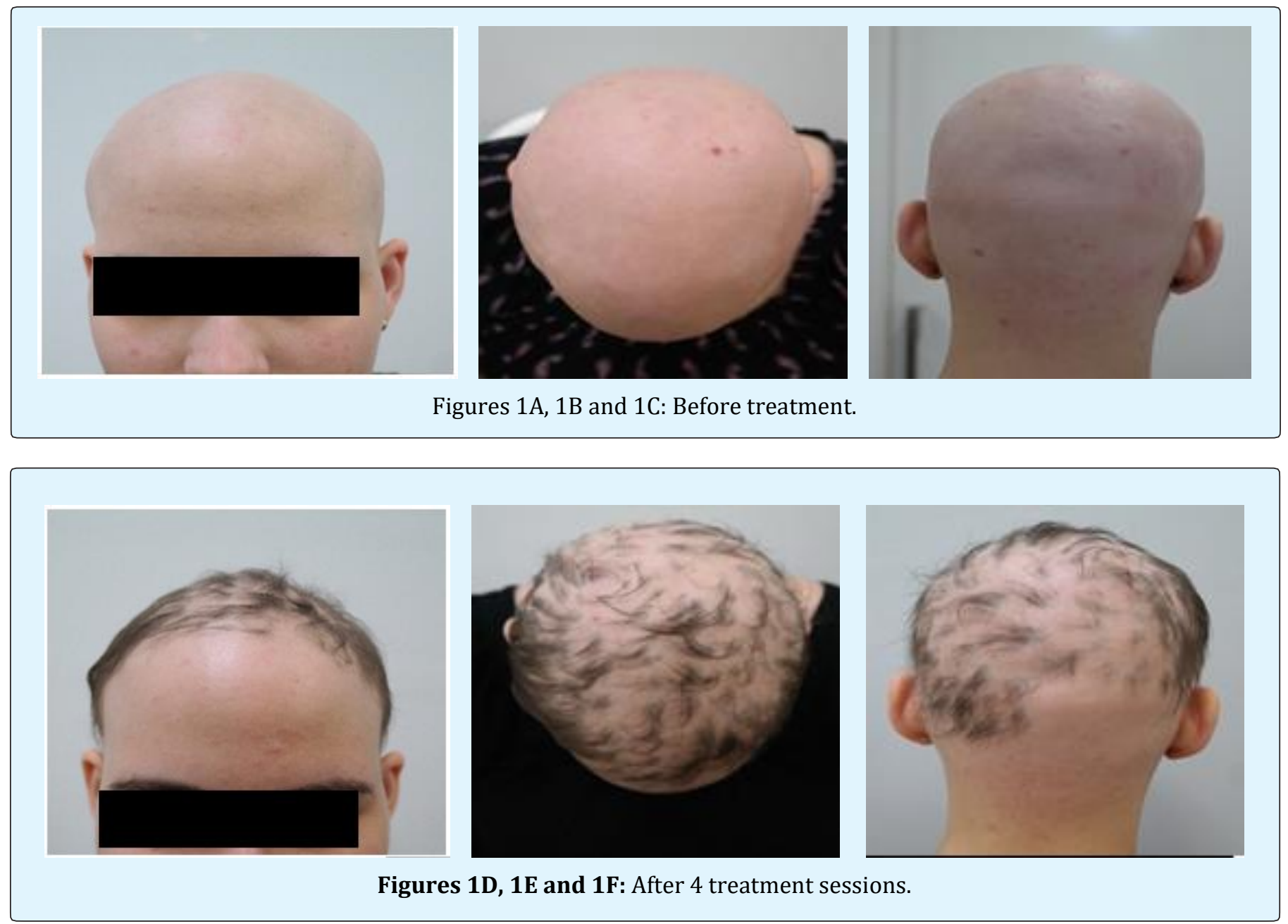


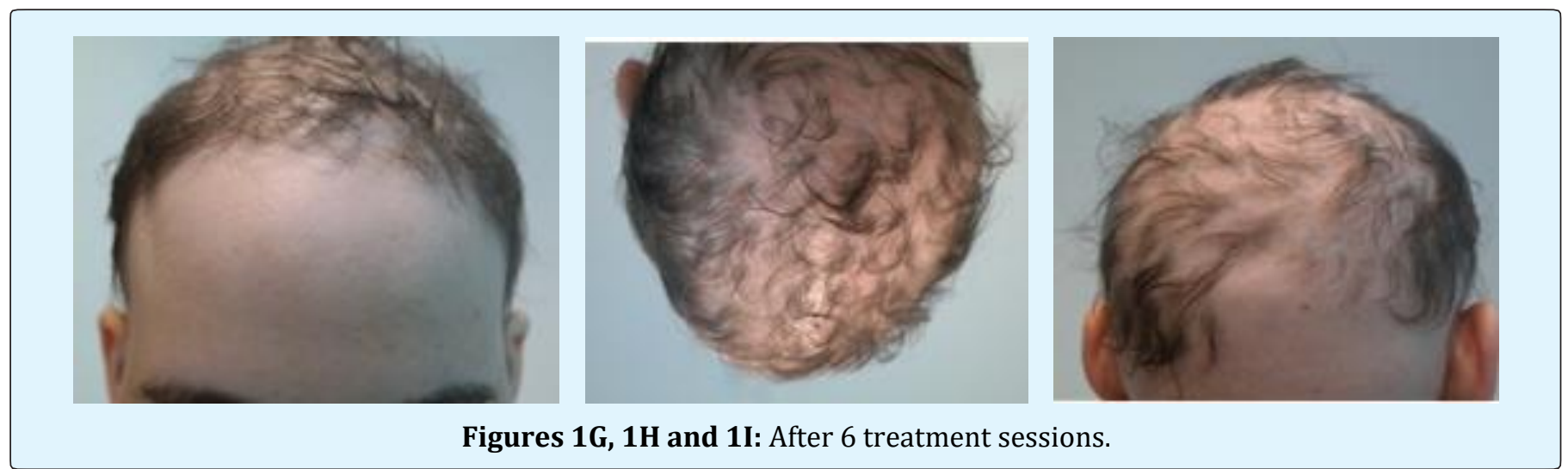

\section{Case 2}

A 59-year old female with a history of 2 years of extensive patchy alopecia areata, underwent treatment with $4 \mathrm{~mL}$ of triamcinolone and lidocaine intralesional injections (Figures $2 \mathrm{~A}-\mathrm{G}$ ). A vibratory device (Brookstone $\left.{ }^{\circledR}\right)$ was used concomitant the injections to minimize the pain. After injections, fractional laser was applied to the entire scalp. The patient underwent 8 sessions. The first 2 sessions were performed every 2 weeks, and the remaining sessions were performed with a 30 days interval. After the $4^{\text {th }}$ session, she developed a few areas of atrophy on the scalp. Those areas were avoided during following injection treatment.

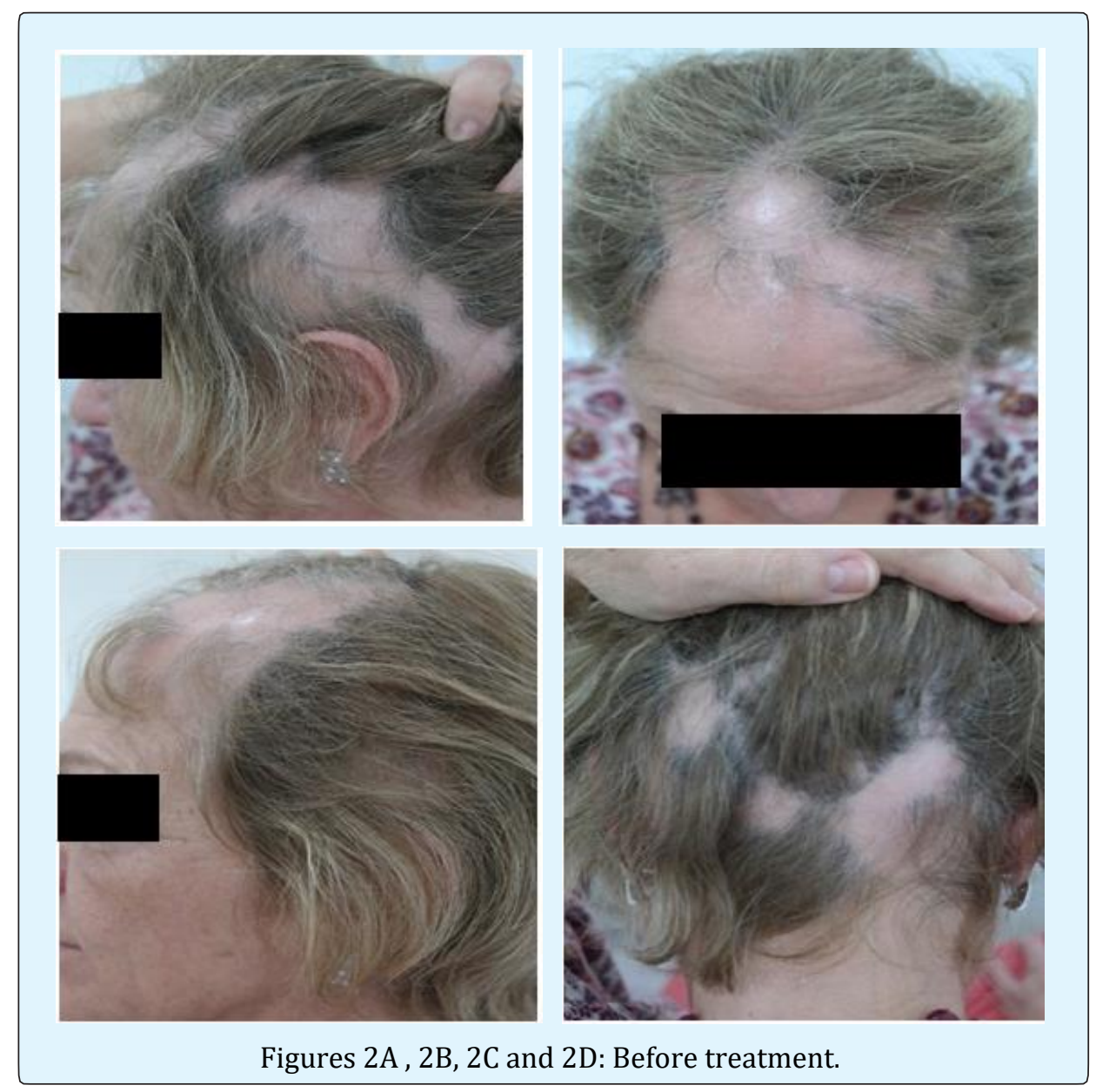



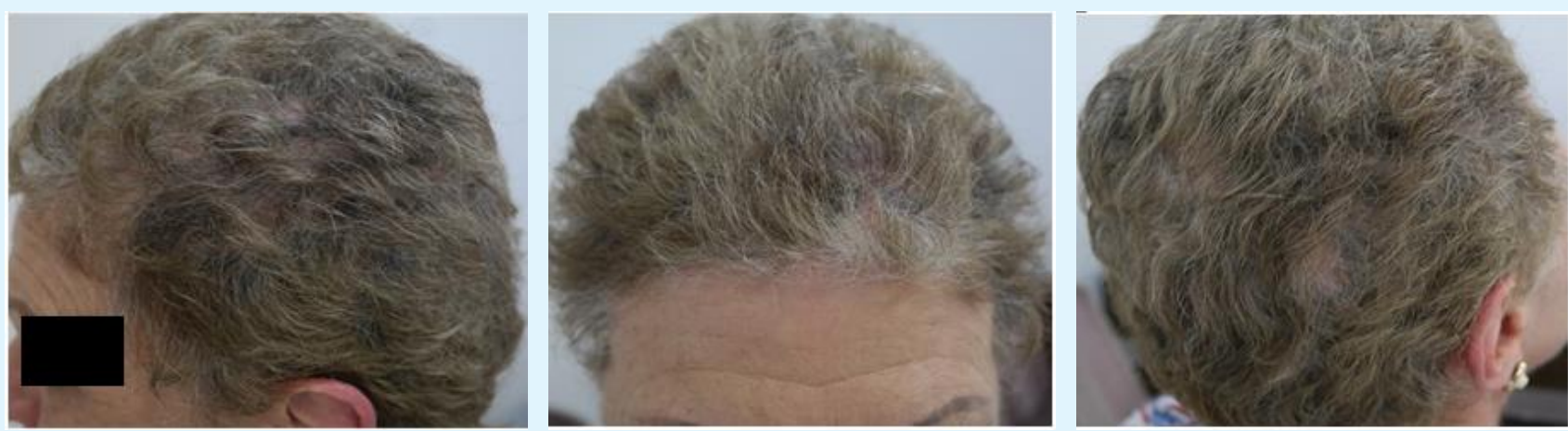

Figures 2E, 2F and 2G: After 8 treatment sessions.

\section{Discussion}

The pathogenesis of AA is complex and not yet completed elucidated, however there is significant evidence indicating the participation of a T-cell mediated autoimmune reaction against hair follicles, targeting actively growing anagen hairs [6]. These findings support the use of steroids as a first line treatment modality for AA.

In extensive disease, systemic steroids are usually preferred, however the side effects and relapse rates can limit its use. The intradermal application of intralesional steroids in low concentration in these cases resulted in minimal atrophy rate. Discomfort during the procedure was reduced with the use of lidocaine and a vibratory stimuli resulting in a minimally painful treatment.

The study of lasers in the treatment of diferente types of alopecia started after the observation of "paradoxal hyperthricosis", in which patients treated with lasers and/or intense pulsed light for photoepilation presented hair growth $[7,8]$.

The stimulation of hair growth during the process of wound healing is another finding that supports the basis for the use of laser to treat hair loss [9].

Fractional laser application is though to induce hair growth by creating microscopic thermal columns in the dermis that induce controlled injury zones. The small wounds formed stimulate changes in cytokines and growth factors expression, allow a rapid epidermal repair and a premature anagen entry $[4,10,11]$. It is postulated that the thermal stimulus could also increase blood flow in the dermal papilla and induce T-cell apoptosis or decrease inflammation $[4,5,12]$. Furthermore, fractional light sources do not cause hair removal because it has no affinity for melanin [5]. The energy is mostly absorbed by water, sparing the superficial layers of epidermis from the excessive thermal damage thus minimizing side effects [13].

Animal studies involving $\mathrm{C} 3 \mathrm{H} / \mathrm{HeN}$ mice suggested that the $1550-\mathrm{nm}$ fractional erbium-glass laser induces hair growth by increasing Wnt 5 a [beta]-catenin signals and augmenting anagen conversion of hair [14].

\section{Conclusion}

The pathophysiology of the lasers that take effect on hair regrowth in AA is still unknown. The interest in studying lasers in the treatment of AA have increased in the past few years. Although the results had been variable, majority of the cases exhibited favorable and positive therapeutic outcomes [13].

The few cases reported in the literature using fractional laser therapy for AA demonstrated no significant side effects $[4,5]$.

Intralesional injections of corticosteroids have been used for several years, with variable results and no significant side effects.

This suggests that intralesional steroids combined with laser application may be a safe and effective combination treatment for extensive AA.

The development of randomized controlled clinical trials with longer follow up periods are needed to establish optimal laser parameters and standardized treatment protocols using either the combination therapy or only laser treatment. 


\section{Clinical Dermatology Open Access Journal}

\section{References}

1. Safavi K (1992) Prevalence of alopecia areata in the First National Health and Nutrition Examination Survey. Arch Dermatol 128(5): 702.

2. Muller S, Winkelmann R (1963) Alopecia areata. An evaluation of 736 patients. Arch Dermatol 88: 290297.

3. Hordinsky MK (2015) Curent treatments for alopecia areata. J Investig Dermatol Symp Proc 17(2): 44-46.

4. Yoo KH, Kim MN, Kim BJ, Kim CW (2010) Treatment of alopecia areata with fractional photothermolysis laser. Int J Dermatol 49(7): 845-847.

5. Eckert MM, Gundin NL, Crespo RL (2016) Alopecia areata: good response to treatment with fractional laser in 5 cases. J Cosmo Trichol 2: 108.

6. Ito T (2013) Recent advances in the pathogenesis of autoimmune hair loss disease alopecia areata. Clin Dev Immunol 2013: 348546.

7. Moreno-Arias G, Castelo-Branco C, Ferrando J (2002) Paradoxical effect after IPL photoepilation. Dermatol Surg 28(11): 1013-1016.

8. Desai S, Mahmoud BH, Bhatia AC, Hamzavi IH (2010) Paradoxical hypertrichosis after laser therapy: a review. Dermatol Surg 36(3): 291-298.
9. Ito M, Yang Z, Andl T, Cui C, Kim N, et al. (2007) Wntdependent de novo hair follicle regeneration in adult mouse skin after wounding. Nature 447(7142): 316320.

10. Manstein D, Herron GS, Sink RK, Tanner H, Anderson RR (2004) Fractional photothermolysis: a new concept for cutaneous remodeling using microscopic patterns of thermal injury. Lasers Surg Med 34(5): 426-438.

11. Werner S, Grose R (2003) Regulation of wound healing by growth factors and cytokines. Physiol Rev 83(3): 835-870.

12. Cho S, Choi MJ, Zheng Z, Goo B, Kim DY, et al. (2013) Clinical effects of non-ablative and ablative fractional lasers on various hair disorders: a case series of 17 patients. J Cosmet Laser Ther 15(2): 74-79.

13. Rangwala S, Rashid RM (2012) Alopecia: a review of laser and light therapies. Dermatol Online J 18(2): 3.

14. Kim WS, Lee HI, Lee JW, Lim YY, Lee SJ, et al. (2011) Fractional photothermolysis laser treatment of male pattern hair loss. Dermatol Surg 37(1): 41-51. 